\title{
Modulações do existir: entre luzes e sombras
}

\author{
Helia Borges ${ }^{\star}$ \\ Faculdade Angel Vianna, Rio de Janeiro, RJ, Brasil
}

\begin{abstract}
Resumo
A partir de um sentido crítico sobre abordagens somáticas, pesquisadores contemporâneos apresentam sintonia com uma clínica que se constitui nos intervalos da comunicação linguageira. A brincadeira de esconde-esconde do infans que faz desaparecimento na ausência conectiva do olhar - o contato olho a olho como lugar de deslizamento para o Fora - aponta para o universo das pequenas percepções que habitam a comunicação intensiva. Ao buscar no conceito de Natureza uma aliança para ampliar o conhecimento sobre o sofrimento humano, Winnicott instaura uma distância crítica ao modelo psicanalítico clássico, restituindo ao pensamento sua dimensão problemática e aproximando-se, desta forma, de clínicos, pesquisadores e filósofos atuais que se posicionam na contramão da condição, cada vez mais violenta, de práticas de assujeitamento.
\end{abstract}

Palavras-chave: pequenas percepções; coemergência; autismo; Winnicott.

\section{Modulations of existing: between lights and shadows}

\begin{abstract}
From a critical viewpoint on somatic approaches, contemporary researchers are attuned to a clinic built in the intervals of language communication. The infantile hide-and-seek play that makes disappearance in the connective absence of the look-the eyeto-eye contact as a slippery place to the Outside -points to the universe of small perceptions that inhabit intensive communication. In seeking the concept of Nature as an alliance to expand knowledge about human suffering, Winnicott establishes a critical distance from the classical psychoanalytic model, restoring to thought its problematic dimension and thus approaching current clinicians, researchers and philosophers who stand against the increasingly violent condition of subjection practices.
\end{abstract}

Keywords: small perceptions; co-emergence; autism; Winnicott.

"Havia muito pouca diferença de significado", diz Autistic Daina Krumins, "entre as crianças ao lado do lago com quem eu estava brincando e a tartaruga sentada no tronco. Parece," continua ela, "que quando a maioria das pessoas pensa em algo que está vivo eles realmente querem dizer: humanos." (MILLER, 2003, p. 23-89 apud MANNINGAND; MASSUMI, 2014, p. 3, tradução nossa). ${ }^{1}$

No seu livro A Natureza Humana, de publicação póstuma, Winnicott (1990, p. 29) nos aponta sua perspectiva do humano: "o ser humano é uma amostra-no-tempo da natureza humana”. Uma proposição enigmática, paradoxal, como são seus escritos que portam a complexidade característica da vida, em toda sua potência de perene transformação.

Esse autor nos lembra, já de saída, a crítica que faz Deleuze, ao trabalhar com a inseparabilidade entre homem e natureza, trazendo de volta para a experiência da vida a inseparabilidade entre a cultura e a natureza, que se manifesta nos corpos em sua receptividade ao mundo.

[...] não existe também distinção homem-natureza: a essência humana da natureza: a essência humana da natureza e a essência natural do homem identificam-se na natureza [...]. Não o homem enquanto rei da criação, mas aquele que é tocado pela vida profunda de todas as formas ou de todos os gêneros, que é carregado de estrelas e mesmo de animais [...]. Homem e natureza não são como dois termos [...], mas uma só e mesma realidade (DELEUZE; GUATTARI, 1972, p. 18-19).

\footnotetext{
* Endereço para correspondência: Faculdade Angel Vianna. Rua Jornalista Orlando Dantas, 2. Rio de Janeiro, RJ - Brasil. CEP: 22231-010. E-mail: borges. helia@gmail.com

1 "There was very little difference in meaning," says autistic Daina Krumins, "between the children next to the lake that I was playing with and the turtle sitting on the log. It seems," she continues, "that when most people think of something being alive they really mean, human"
}

Rompendo com a lógica cientificista que transforma a condição trágica da existência em argumentações de seriedade, Winnicott restaura o trágico ao refletir sobre os paradoxos na constituição do sujeito, e ao evidenciar as torções que sofre o pensamento do homem moderno na alienação pela primazia da racionalidade. Evidencia também aqui sua recusa aos dogmas nos quais, por tantas vezes, a própria psicanálise se vê envolvida.

Em A Natureza Humana, o autor nos diz que habitamos "um mundo não desejado" (WINNICOTT, 1990, p. 26), o que nos retira, de imediato, de toda uma concepção de mundo mergulhada na negatividade. Negatividade que se sustenta em uma visão de mundo definida pela antecipação, que imprime sentido para a vida. Para Winnicott, o ser emerge "para" a vida, num enfrentamento com um mundo que não desejou e essa condição lhe permitirá se constituir como força de enfrentamento, positivando a existência. Segundo ele, "a partir da interação com o ambiente, surge um emergente, o indivíduo que procura fazer os seus direitos, tornando-se capaz de existir num mundo não desejado" (WINNICOTT, 1990, p. 26).

Ser "uma amostra-no-tempo" da natureza humana é a afirmação que nos restaura a dimensão de alteridade inscrita na própria lógica da existência. Implicado na crítica à dualidade entre psíquico e somático, o autor faz ver a condição da vida como positividade: "nature e nurture: hereditariedade e criação" (WINNICOTT, 1990, p. 29). A psique não é outra coisa que a invenção a partir de uma relação ao soma; as experiências vividas no corpo como objeto ou matéria da alma. O corpo se inscreve na alma.

A natureza, para Winnicott, é ao mesmo tempo uma potência final de realização e a necessidade de afirmar o existente. Podemos afirmar que a natureza humana "para 
Winnicott se aproxima da ideia de condição humana nomeada por Hanna Arendt e que poderíamos talvez traduzir pela: condição do humano" (DAVID-MÉNARD, 2006, p. 161). Ou ainda, do "mais-que-humano", como nos dizem Manningand e Massumi (2014), ao problematizarem, a partir de pesquisas com autistas, a perda perceptiva de mundo dos neuropáticos ${ }^{2}$ (conf. MANNINGAND; MASSUMI, 2014). Essa assertiva convoca a questão fundamental e ética sobre a imersão do ser no ambiente no movimento realizado em direção à vida.

Por "homem-que-somos" e "mais-que-o-humano", evidencia-se o estado de ultrapassagem do que se constituiu a partir do pensamento dissociado do corpo, em ruptura com o homem identitário, o homem interiorizado, colonizado.

"Formato-homem" foi termo utilizado por Estamira, personagem do filme Estamira (2004), para falar de si: formato homem par (mulher), decorrente dos processos de subjetivação, não só em relação ao gênero, mas ao que tem sido considerado humano, tem como resultante a alienação da capacidade de captação de uma ambiência no ato de conhecimento, de modo que exclui a perspectiva ética da existência que se expressa na diversidade, na diferença, no desvio.

Ao contrário desse formato homem, são os trajetos de errância experienciados que nos permitem mergulhar em novos planos e, pelo eclipse do eu, acessar um mundo prévio ao discurso, retirando o conhecimento de um vetor que parte do sujeito para o objetivo e rendimento, liberando o conhecimento para um campo de afetabilidade, possibilitando a multiplicação dos vetores e pontos de vista.

Ao colocar em cena a Natureza como parte do $\mathrm{Hu}-$ mano, Winnicott parece querer devolver para vida do homem o que dela foi retirado; devolver ao homem da razão, propriamente, uma lógica que não se pautaria no privilégio da racionalidade. Evidencia através da experiência do infans o tateio, a visão háptica que pressupõe as sensorialidades na captação do conhecimento, a geografia de um campo no seu processo de vir a ser.

E é ainda esse autor, em sintonia com a experiência do existir, quem ressalta que o nascimento e a morte atravessam todas as atividades humanas como suas condições, apontando a condição política da existência (WINNICOTT, 1990).

Para Hanna Arendt, "agir, em nossa sociedade de homens guarda a característica do que começa como uma criança que inaugura vida" (DAVID-MÉNARD, 2006, p. 163). Neste sentido, a natureza humana de Winnicott nos fala de que o existente, ao ser atravessado pelo mundo, pode conquistar a possibilidade de sustentar a vulnerabilidade, condição necessária para ser receptivo à diferença. A condição humana estaria aí, nesta capacitação para vida a partir de um devir-infância, que nos colocaria em um campo comum, descentralizando a lógica narcísica fundada no Eu.

\footnotetext{
${ }^{2}$ Termo utilizado pelos pesquisadores que trabalham com autistas para diferencia a qualidade de percepção entre autistas e os "normais" sustentados no senso comum e no bom senso (MANNINGAND; MASSUMI, 2014).
}

Devir-infância como na criança pequena que ainda não domina a palavra e que, na brincadeira de esconde-esconde, ao vendar os olhos revela sua condição de engate com o meio ambiente através da imersão, a partir sua coexistência: o outro desaparece quando não há conectividade através da visão háptica. É o campo intensivo, o experimentado na brincadeira onde o outro desaparece ou reaparece pelo olhar desconectado ou conectado a outro olhar.

O interesse é pelos começos e não pelas origens. Tal deslocamento incessante da existência enquanto campo de criação aponta para a vida em uma interminável variação, intensa germinação de mundos, dentro de uma lógica de continuidade. É, portanto, atributo de cada existente, ser um aprendiz de seu próprio plasma germinativo, segundo aportes de vários estudiosos e ativistas da causa dos autistas, que colaboram, significativamente, para as ideias trazidas por Winnicott.

Essas contribuições colocam em cena a condição de marginalização que se sustenta em determinado modo de existir que não se configura nos padrões do que é considerado um comportamento normal (neuropático). Assim, podemos tomar contato com alguns aportes descritos a seguir, no intuito de construir pensamento, a partir da frase winnicottiana "o ser humano é uma amostra-no-tempo da natureza humana", sobre o que parece apontar para a característica imanente da própria vida.

Segundo esses pesquisadores, a maior parte das pessoas (neuropáticos) percebe o mundo através de uma valorização do expresso humano (por exemplo: escutar a voz destacadamente em um todo percebido) em detrimento de outras manifestações que se apresentam no campo perceptivo, colocando as coisas do ambiente em segundo plano (vide a epígrafe deste texto). Para alguns destes pesquisadores, o autismo é visto como portador do que se denomina uma "cegueira mental", definida como uma inabilidade em desenvolver a consciência da existência do outro, uma incapacidade de estabelecer uma comunicação sutil.

Porém, para os pesquisadores, o autista não rejeita o humano nem foge do relacionar-se. Pelo contrário, o que se testemunha no autista é um engajamento com o "mais-que-humano", um engajamento à vida. Manningand e Massumi (2014) nos trazem o texto de Miller, em que este evoca a comunicação da autista Daina Krumins:

"Observo tudo da mesma maneira sem discriminação, de modo que o grasnado do corvo na árvore é tão claro e importante como a voz da pessoa com quem ando" [...] E num envolvimento com um estilo mais relacionado a texturas: "Meu mundo está organizado em torno de texturas [...] Todas as emoções, percepções, meu mundo inteiro [...] [foi] influenciado por texturas" (MANNINGAND; MASSUMI, 2014 , p. 3, tradução nossa). ${ }^{3}$

Texturas são padrões, são contrastes, luzes e sombras, movimentos, gradientes e transições; aquilo que se coloca fora de uma percepção linear, sem intervalos, focada, característica do pensamento racionalizado. Uma disper-

3 "I attend to everything the same way with no discrimination, so that the caw of the crow in the tree is as clear and important as the voice of the person I'm walking with" [...] And an engagement with a more textured relating: "My world is organized around textures[...] All emotions, perceptions, my whole world [...] [has]been influenced by textures" 
são do foco, não uma falta de atenção com a vida, com o escopo da vida em sua complexidade. Nos intervalos, nos vazios que se abrem na percepção não linear, a vida se expressa de modo não hierarquizado entre o orgânico e o inorgânico, as cores, os sons, os cheiros, os ritmos percepções e emoções se inter-relacionam, o que permite experimentar em plenitude o que Manningand e Massumi (2014) chamam de "a dança da atenção".

A "dança da atenção" nos fala da característica perceptiva em que o ato perceptivo está em uma imersividade; ela não está focando algo, não está se dirigindo para algo, e sim tateando uma posição. $\mathrm{O}$ ato perceptivo contempla o movimento inscrito no próprio ato de perceber. Este modo de captar mundo da "dança da atenção" é poder entrar num modo de consciência do ambiente, em que perceber é sentir que a percepção consiste em uma ação que é guiada através de estruturas cognitivas que emergem da experiência da senso-motricidade na relação corpo-ambiente. Uma ação mútua, co-movimento, co-moção, percepção sustentada num campo de imediaticidade característica da percepção emergencial. Uma emergência contínua, uma germinação florescendo.

Nesta perspectiva, não há separação entre o objeto percebido e o meio no qual este se vê inserido, mas em co-atividade, de modo diverso como é para o "neurotípico", em que a percepção está tomada por pré-juízos e fechada à infiltração das interferências sutis, como modulações, cheiros, luzes e sombras, gradientes do percebido. Em oposição a esta perspectiva, no autista a percepção se dá na imersão, no engajamento com o ambiente em uma mutualidade:

Um florecimento da dança da atenção como o acontecimento desta imersão. O jasmim reúne o jogo de cor e sombra em torno de si mesmo, transmutado em uma interação de umidade e luz. Luz e umidade, em co-movimento com um cheiro. A fragrância do jasmim - em sua interação com a umidade e a luz, leva a retransmissão das sombras coloridas como a qualidade predominante do campo de composição como um todo. Esta retransmissão traz o campo para o limiar de uma expressão determinada (MANNINGAND; MASSUMI, 2014, p. 5, tradução nossa). ${ }^{4}$

Desde a perspectiva da percepção de um jasmim florescendo no jardim, a fragrância se co-move com a luminosidade no interjogo de luz e sombra como transmissão do sinal em um campo dinâmico, um circuito de comunicação-transdução, onde a qualidade colorida, como qualidade predominante do campo como um todo, emerge. Porém, no "neurotípico", o apelo é para perceber o cheiro antes da flor, pois já está pré-formada a ideia de que a flor é para cheirar, fechando o tempo de experiência na medida em que este já está misturado com as informações que definem as experiências.

\footnotetext{
${ }^{4}$ A flowering dances to attention as the event of this ingression. Jasmine gathers the play of color and shadow around itself, transmuted into an interplay of moisture and light. Light and moisture, in co-motion with a smell. The fragrance of jasmine, in its interplay with moisture and light, takes the relay from colored shadow as the predominant quality of the compositional field as a whole. This relay brings the field to the verge of determinate expression.
}

Para o autista, a flor e o ambiente não são separados, mas constituídos juntamente, como ritmos do ambiente, ritmos corpo e ambiente constituídos coativamente, em que os modos dos existentes não se definem previamente à experiência, não materializando o ser através do que já está constituído. Envolvem, portanto, em sua emergência os eventos singulares em que o objeto está sendo constituído: o modo compõe o ser.

Esta leitura do modo autista de ver o mundo expressa a riqueza perdida pela diferença que caracteriza o ato perceptivo do formato homem - como nos diz a personagem Estamira, aponta para a prisão a que fomos assujeitados nos processos racionalistas que priorizam o humano, dissociando-o no entorno.

E é nestes termos que Winnicott nos chama atenção, através da comunicação sutil da díade mãe-bebê, instauradas pela mutualidade; não são apenas os cuidados mais evidentes que serão alvo de atenção, mas aspectos discretos da comunicação sutil que apontam as necessidades específicas de um ser emergente. Pelas conexões empáticas, pelas conexões estésicas, vividas no encontro, seria possível acessar os modos de existência, em seus ritmos, via pequenas percepções, nas modulações, gradientes, entre luzes e sombras.

Neste pequeno trecho do livro A Natureza Humana, Winnicott (1990, p. 147-148) se questiona se haveria, para o bebê, um conhecimento prévio antes do nascimento:

Devemos presumir que antes do parto, o bebê já seja capaz de reter memórias corporais, pois existe uma certa quantidade de evidências de que a partir de uma data anterior ao nascimento, nada daquilo que o ser humano vivencia é perdido. Sabemos que, no útero os bebês realizam movimentos natatórios de um peixe. As mães dão intenso valor à atividade de seus bebes [...] é possível a existência de uma organização central que seja capaz de perceber essas experiências.

Existem, portanto, traços mnêmicos que estarão atravessando a vida em formação. Para Winnicott, a mãe começa a sentir a existência da vida em seu útero quando o bebê desencadeia as articulações e as movimentações. A questão que aqui se coloca não é, absolutamente, decidir sobre a existência, necessária ou não (e seus resultantes) de uma mãe biológica para captar este universo do infans, mas buscar ampliar um saber sobre como se daria tal percepção que se realiza através destes movimentos característicos "e por que/para que" Winnicott nos chama atenção para esse fato.

O que parece estar em jogo aqui, desse ponto de vista, seria a possibilidade de conceituar a experiência de comunicabilidade de modo ampliado, partindo do modo redutor em que está constituída - através do eixo lógico-racional -, para nos permitir uma aproximação da comunicação sustentada na experimentação, nos ritmos, desvios e deslocamentos no corpo. Tomando Leibniz em Deleuze (2000), voltamo-nos para o campo das pequenas percepções, as micropercepções, no sentido de favorecer uma ponte para mergulhar nas provocações winnicottianas. 
Segundo Deleuze, Leibniz nos diz que há um obscuro em nós, não só porque temos um corpo, mas temos um corpo porque há um obscuro em nós que exige um corpo, um fundo sombrio do espírito. Contrapondo a ideia cartesiana do cogito, produz uma existência atravessada pelo modo sombrio de ser, afirmando que existe uma zona clara que necessita percorrer o sombrio e que este percurso se dá através do corpo. E esse obscuro captado pelo corpo são as micropercepções.

Assim, pergunta Deleuze (2000, p. 147): “como o que expresso clara e distintamente pode ter relação com meu corpo, cujos movimentos são todos conhecidos obscuramente?".

Partindo da afirmativa de Winnicott, podemos dizer que, quando o bebê está dentro do útero, a mãe contempla a atividade dele pela experiência, pelo ritmo dos movimentos que se desdobram pelos micromovimentos. Existe um movimento propulsor no bebê que faz com que se realizem movimentos a partir dos micromovimentos, uma produção de movimentos que são produção de vida e que está inscrita no corpo a partir de sua trajetória de constituição espaço-temporal.

São relações diferenciais, são qualidades expressivas, são gradações, são modulações que vão sendo captadas e formam as singularidades. O ser puxa para si o que faz sentido para ele. Os organismos se reorganizam sempre, desarticulando um ponto estático, centro gravitacional para ocupar novo território. A articulação que se paralisa gera um ponto de parada para pulsionar o corpo em uma nova direção. $\mathrm{O}$ acontecimento é composição com o corpo e é uma dobra: um crivo que sai do caos, que modifica o modo de estar na vida.

As micropercepções, ou os representantes do mundo, são estas pequenas dobras em todos os sentidos [...] São estas pequenas percepções obscuras confusas, que compõem nossas macropercepções, nossas percepções conscientes, claras e distintas: uma percepção consciente jamais aconteceria se ela não integrasse um conjunto infinito de pequenas percepções [...] Como uma fome sucederia a uma saciedade se mil pequenas-fomes elementares (de sais, de açúcar, de gordura etc.) não se desencadeassem de acordo com ritmos diversos, desapercebidos? (DELEUZE, 2000, p. 147-148).

Evidencia-se aqui esse campo de comunicabilidade, sutil, em que a lógica semiotizada do signo linguageiro do discurso não comunica. Então como a mãe, ou aquele que se dispõe ao cuidado, consegue ter uma luz de consciência a partir das micropercepções, como se passa das pequenas percepções às percepções conscientes? O problema que se coloca, portanto, é como dar forma às forças?

É ainda em Leibniz, segundo Deleuze (2000), que encontramos uma possibilidade de responder a esta questão que se encontra, justamente, no ultrapassamento do senso comum, do que já está significado e convoca a potência de criação adormecida. A comunicação do bebê com a mãe, que consegue ter uma luz de consciência oriunda a partir dos movimentos do bebê, estaria no campo das articulações diferenciais entre as micropercepções de modo tal que o ambiente (função mãe) será capaz de prover, de dar um retorno ao bebê para que o processo de dar sentido possa se desdobrar.

Seja a fome: é preciso a falta de açúcar, que a falta de gordura, etc. entrem em relações diferenciais que determinem a fome como algo relevante ou notável. Seja o ruído do mar: é preciso que pelo menos duas vagas sejam um pouco percebidas como nascentes e heterogêneas para que entrem numa relação capaz de determinar a percepção de uma terceira, da que excele sobre as outras e torna-se consciente. (DELEUZE, 2000, p. 150).

É preciso, portanto, que ocorram relações diferenciais entre os elementos, ou seja, que se estes se articulem em suas diferenças, nas suas pequenas percepções, para que haja percepção do movimento, para que ocorram as macropercepções.

O campo intensivo, campo das forças, molecular, se dá a perceber implicado num estado de ser-com-o-mundo, não simbiótico, mas extenso, num deslocamento constante entre o dentro e o fora, através do qual as experiências seriam vividas como uma experiência globalizada, em que o percebido seria apreendido de forma única e singular, de modo a captar o que se coloca assemiotizado: experiências estéticas que se realizam pelo deslocamento, presentes nos gestos e na força poética rítmica dos discursos do outro.

O que se abre, portanto, não é o sentido como senso (sensação), mas aquilo que nos possibilita, a partir do empírico, captar o concreto, a coisa em si, para criar outros sentidos. É através das pequenas percepções que Deleuze vai operar o campo de afetação no qual nos vemos inscritos, propondo-nos uma aproximação do ínfimo no encontro que evidencia a redução operada na percepção do senso comum.

[...] o percebido assemelha-se alguma coisa na qual ele nos força pensar. Tenho uma percepção branca percebo branco: esse percebido assemelha-se a espuma, e isto é, há uma infinidade pequenos espelhos que refletiriam sobre nossos olhos um raio de luz. Sinto uma dor: esta dor se assemelha ao movimento de alguma coisa pontiaguda que nos escava carne em círculos centrífugos (DELEUZE, 2000, p. 161).

Assim, podemos afirmar - como já descrito neste artigo, na experiência do autista, ou na mutualidade íntima vivida entre a mãe e o bebê -, que se evidencia que o percebido se dá para além do objeto - o alfinete, no caso da citação acima. Há um modo de conhecimento, no encontro com o objeto, que não se restringe ao objeto separado da experimentação vivida, na estesia, na experiência estética vivida no "como" das intensidades que o alfinete produz ao se conectar com o corpo.

Partindo desta perspectiva, perguntamo-nos se não seria vital reivindicar a fisicalidade da voz na palavra: como a criança que antes de pronunciar um sentido experimenta o prazer com suas ecolalias, balbucios, buscando o corpo sonoro da infralíngua, ${ }^{5}$ aí onde o sentido é secundário.

5 Segundo Gil (1980), a infralíngua diz daquilo que ainda não se atualizou, lugar assignificante, assemiotizado, força que turbilhona os significados.

Fractal, Rev. Psicol., v. 29 - n. 2, p. 191-195, 2017 
Para se comunicar a partir das afecções, é preciso liberar o pensamento de suas amarras conceituais, de modo a poder forçar o pensamento a pensar. Pensar é criar, fazer nascer o que o que já existe, mas que, invisível, não pode ser percebido desde um modo de pensar que se exclui do mundo, da vida; vida em que bailam os existentes orgânicos e inorgânicos em suas múltiplas diferenças, seres aberrantes.

Tanto na fala do autista, como no olhar do infans (antes da fala) que brinca de desaparecer, a experiência de estar submerso, mergulhado, nos retira do parto da subjetividade assujeitada, desliza na imanência da vida... Se aqui nos referimos a esta condição da existência que resgata as modulações nos trajetos percorridos, é para ressaltar que, para além das prisões conceituais, intelectuais, as experimentações com a existência nos fortalecem para atravessar a colonização que nos habita.

Virilio (2015) nos fala da perspectiva do cinema, onde a lentificação do tempo permite que algo novo se instaure. Não uma invenção de algo que não exista, mas um modo de apreender o que antes não poderia ser visível. Assim como observar uma flor na experiência do autista - por não estar submetido à ordem do foco, é dar a ver um campo que se constitui na abertura para o acontecimental de cada evento, a flor não é vista como uma individualidade, mas como um campo de ressonâncias onde a luz, o odor, a temperatura, os fluxos de tempo e espaço se fazem presentes. Estados emergentes... são estes que inoculam ninhos de criação.

\section{Referências}

DAVID-MÉNARD, M. Human nature $o u$ human condition. In: CYSSAU, C.; VILLA, F. (Org.). La nature humaine à l'epreuve de Winnicott. Paris: PUF, 2006. p. 159-164.

DELEUZE, G. A dobra: Leibniz e o Barroco. São Paulo: Papirus, 2000.

DELEUZE, G.; GUATTARI, F. O Anti-Édipo. Rio de Janeiro: Imago, 1972.

ESTAMIRA. Direção: Marcos Prado. Produção: José Padilha e Marcos Prado. Rio de Janeiro: Riofilme, 2004. 1 DVD (127 $\min )$.

GIL, J. Metamorfose do corpo. Lisboa: Relógio d’Água, 1980.

MANNINGAND, E.; MASSUMI, B. Thought in the act: passages in the ecology of experience. Minneapolis: University of Minnesota, 2014.

VIRILIO, P. Estética da desaparição. Rio de Janeiro: Contraponto, 2015.

WINNICOTT, D. A natureza humana. Rio de Janeiro: Imago, 1990.

Recebido em: 4 de abril de 2017

Aceito em: 9 de junho de 2017 